Provided for non-commercial research and education use. Not for reproduction, distribution or commercial use.

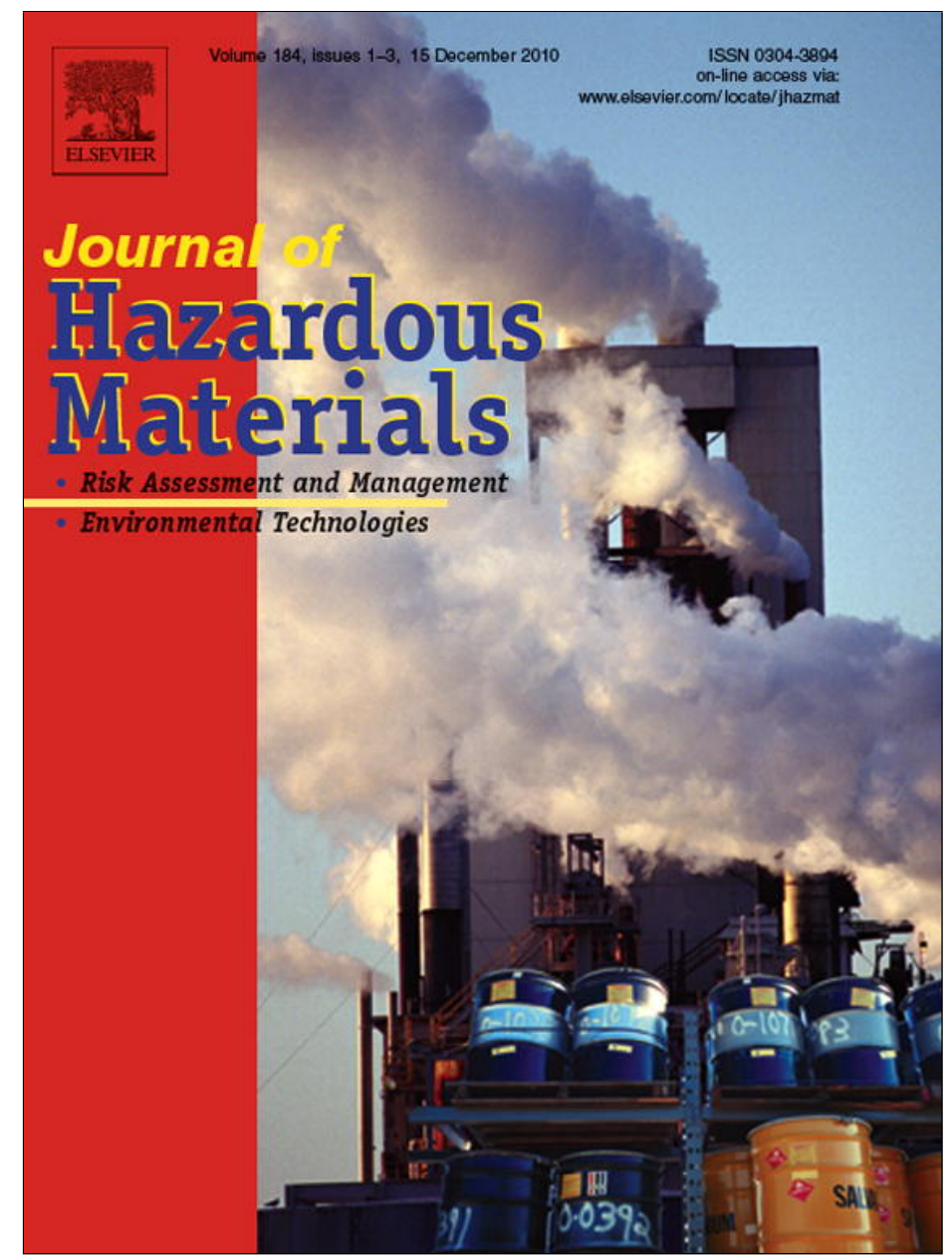

This article appeared in a journal published by Elsevier. The attached copy is furnished to the author for internal non-commercial research and education use, including for instruction at the authors institution and sharing with colleagues.

Other uses, including reproduction and distribution, or selling or licensing copies, or posting to personal, institutional or third party websites are prohibited.

In most cases authors are permitted to post their version of the article (e.g. in Word or Tex form) to their personal website or institutional repository. Authors requiring further information regarding Elsevier's archiving and manuscript policies are encouraged to visit:

http://www.elsevier.com/copyright 


\title{
Biological treatment of PAH-contaminated sediments in a Sequencing Batch Reactor
}

\author{
Agostina Chiavola ${ }^{\mathrm{a}, *}$, Renato Baciocchi ${ }^{\mathrm{b}}$, Renato Gavasci ${ }^{\mathrm{b}}$ \\ a Department of Hydraulics, Transportation and Roads, Faculty of Engineering, University of Rome Sapienza, Via Eudossiana, 18, Zip code 00184, Rome, Italy \\ ${ }^{\mathrm{b}}$ Department of Civil Engineering, Faculty of Engineering, University of Rome Tor Vergata, Via del Politecnico 1, Zip code 00133, Rome, Italy
}

\section{A R T I C L E I N F O}

\section{Article history:}

Received 5 February 2010

Received in revised form 13 July 2010

Accepted 5 August 2010

Available online 13 August 2010

\section{Keywords:}

Oxygen uptake rate

Polycyclic aromatic hydrocarbons (PAHs)

Sequencing Batch Reactor

Sediments

Slurry

\begin{abstract}
A B S T R A C T
The technical feasibility of a sequential batch process for the biological treatment of sediments contaminated by polycyclic aromatic hydrocarbons (PAHs) was evaluated through an experimental study. A bench-scale Sediment Slurry Sequencing Batch Reactor (SS-SBR) was fed with river sediments contaminated by a PAH mixture made by fluorene, anthracene, pyrene and crysene. The process performance was evaluated under different operating conditions, obtained by modifying the influent organic load, the feed composition and the hydraulic residence time. Measurements of the Oxygen Uptake Rates (OURs) provided useful insights on the biological kinetics occurring in the SS-SBR, suggesting the minimum applied cycle time-length of 7 days could be eventually halved, as also confirmed by the trend observed in the volatile solid and total organic carbon data. The removal efficiencies gradually improved during the SS-SBR operation, achieving at the end of the study rather constant removal rates above $80 \%$ for both 3-rings PAHs (fluorene and anthracene) and 4-ring PAHs (pyrene and crysene) for an inlet total PAH concentration of $70 \mathrm{mg} / \mathrm{kg}$ as dry weight $(\mathrm{dw})$.
\end{abstract}

(C) 2010 Elsevier B.V. All rights reserved.

\section{Introduction}

PAHs are a class of toxic pollutants that accumulate in the environment due to both natural and anthropogenic activities such as the incomplete combustion of organic matter and fossil fuels, the accidental spilling of processed hydrocarbons and oils, coal liquefaction, organic oil seepage and surface run-offs from forest-brush fires and natural geological processes [1]. These compounds are of great public concern due to their persistence in the environment and potentially deleterious effects on the environment and on human health.

Treatment of PAH-contaminated sediments can be performed by means of different technologies, which focus either on concentrating PAHs in a limited volume or on chemical or biological conversion of the contaminant [2-4]: these may include solvent extraction, thermal treatment [4], chemical oxidation [5], as well as landfarming or bioremediation, in more general terms. In the latter method, the biodegradation potential of microorganisms is maximized in order to achieve rapid removal of the contaminants with minimum disturbance and negative impact to the environment.

Aerobic biodegradation of low molecular weight PAHs by bacteria and microorganisms has been documented by various authors,

\footnotetext{
* Corresponding author. Tel.: +39 06 44585370; fax: +39 0644585041 E-mail addresses: agostina.chiavola@uniroma1.it (A. Chiavola), baciocchi@ing.uniroma2.it (R. Baciocchi), gavasci@ing.uniroma2.it (R. Gavasci).
}

but high-molecular weight PAHs (with five or six aromatic rings) have proven to be more recalcitrant to biological degradation [5]. PAH-removal rate and extent of mineralization have also been shown to depend on the number and position of substituent groups and on the saturation grade of the aromatic rings [6]. Microbial degradation of PAHs and other hydrophobic substrates is believed to be limited by the amounts dissolved in the water phase, with sorbed, crystalline, and non-aqueous phase liquid (NAPL) PAHs being unavailable to PAH-degrading organisms. Lower molecular weight PAHs typically exhibits higher aqueous solubility and weaker sorption onto the sediment, thus explaining why their biodegradation is more effective and efficient [7]. Bioremediation in slurry phase has been shown to improve the removal efficiency with respect to other bioremediation options, since it allows to perform the biodegradation process under controlled conditions, by accurately regulating oxygen, nutrient level and temperature [8]. While slurry reactors have been applied in soil bioremediation projects, their use for the treatment of PAH-contaminated sediments has been limited [9]. The biodegradation efficiency was observed to be influenced by different operating parameters, such as the slurry loading rate, the quantity and quality of detergents added to the reactor, the aging of the contamination and the strain selection. PAH-degrading microorganisms originally present in the sediment allowed to achieve remarkable biodegradation (biotransformation) of two-, three-, four-, and five-ring PAHs, provided that a sufficient supply of oxygen was guaranteed; on the contrary, no apparent degradation of six-ring compounds was observed [7]. 


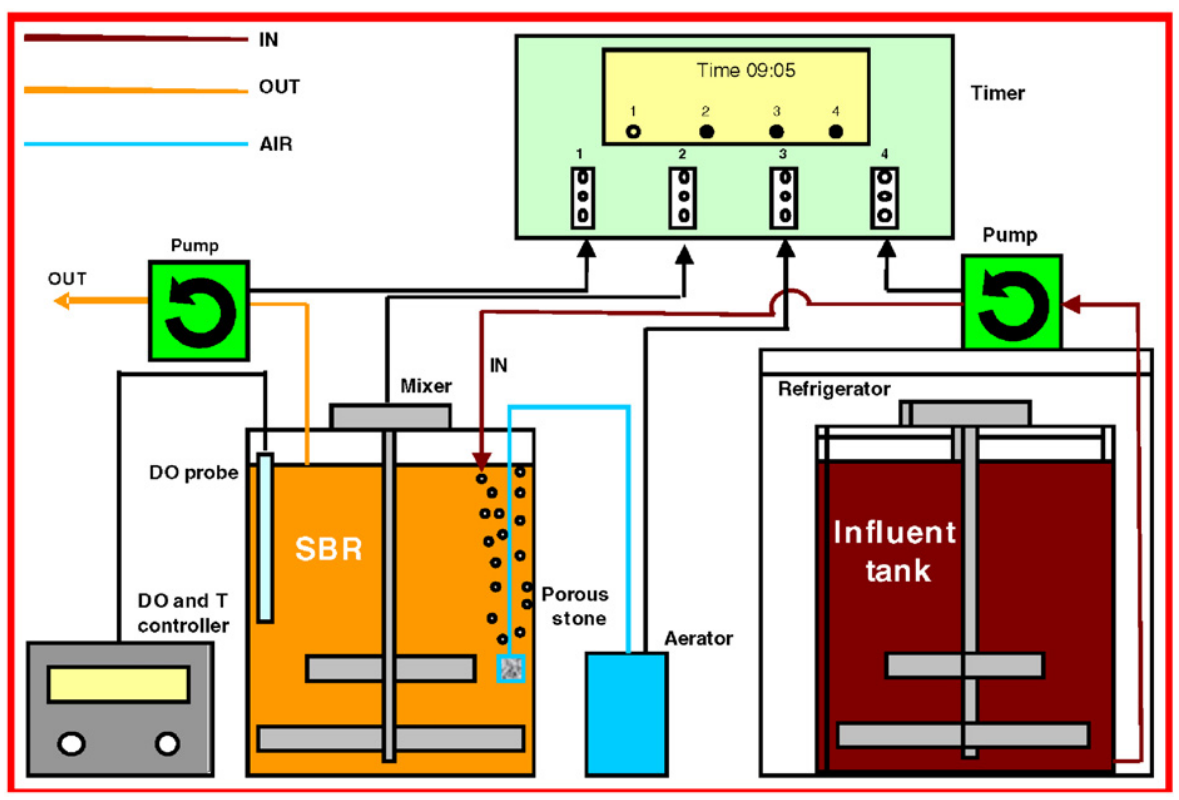

Fig. 1. Sketch of the bench-scale SS-SBR plant.

Addition of bacterial strains of known PAH-degradative capabilities allowed to speed up the rate of biodegradation [10,11].

As far as the reactor configuration is concerned, the bioslurry process has been carried out using the continuous flow-completely stirred tank reactor (CSTR) [12], the Sequencing Batch Reactor (SBR) [12] as well as batch systems [13].

In the present study, the SBR technology was selected among different alternatives due to its widely proved ability in the depuration of streams containing toxic or bio-recalcitrant compounds [14-18]. With respect to the typical cycle of a SBR for wastewater treatment, in the Soil or Sediment Slurry SBR (SS-SBR) no settle phase is foreseen, whereas, at the end of the react phase, a known volume of slurry is withdrawn from the tank and discharged or eventually delivered to a further treatment process. The most important operating factors influencing the SS-SBR removal efficiency are the Hydraulic Retention Time (HRT), the volume of slurry replaced at the end of each cycle (volumetric exchange rate, VER), the solids concentration and the mixing speed. Despite the huge literature on wastewater treatment by SBR, to our knowledge there is only one work on the application of the slurry-phase SBR reactor to the treatment of hydrocarbon-contaminated sediments [19]. The feasibility of this process was demonstrated on a real sediment, although slightly contaminated by PAHs (below $20 \mathrm{mg} / \mathrm{kg}$ ), but no investigation on the influence of the feed concentration on the process efficiency was performed.

The present paper shows the results obtained through an experimental activity carried out on a bench-scale SS-SBR for the treatment of PAHs-contaminated sediments in a slurry phase. Different operating conditions and increasing PAHs concentrations in the sediments were investigated and the corresponding removal efficiencies along with the oxygen consumption rates determined. Real sediments from a contaminated site were used; however, due to the very low PAH concentration initially present, they were spiked with a mixture, made by PAHs potentially amenable for biodegradation, characterized by a rather low number of aromatic rings. Fluorene, anthracene and pyrene were initially selected, whereas crysene, that is a less biodegradable compound, was included in the PAH mixture only in a second stage, when stable and reliable process performances had been achieved.

\section{Materials and methods}

\subsection{Experimental SS-SBR}

The experimental activity was carried out in a pyrex-made vessel with $5 \mathrm{~L}$ working volume ( $7 \mathrm{~L}$ total volume), upper closed with a stainless steel flange (Fig. 1). The reactor was equipped with peristaltic pumps for feeding the contaminated slurry at the beginning of each fill phase and for drawing the treated slurry at the end of each react phase. Air was supplied through a porous stone placed within the reactor close to the bottom and connected to an external aeration system. During the react phase, the reactor was continuously mixed by means of a mechanical mixer. All the electromechanical equipments were automatically controlled through a timer. The reactor was maintained under temperature-controlled conditions by a circulating water bath, with $T=20 \pm 2{ }^{\circ} \mathrm{C}$.

\subsection{Sediments}

Sediments used for the experimental study were collected at an Israeli contaminated site in the framework of an Italian-Israeli cooperation on environmental technologies, aimed to the development of an integrated approach for the remediation of polluted river sediments. The bulk sediments were stored in a sealed dark container at $4{ }^{\circ} \mathrm{C}$ in order to prevent the occurrence of photo- and bio-oxidation. Sediments were initially characterized for their texture, grain size, humidity, $\mathrm{pH}$, volatile and fixed solids (VS and FS, respectively), total organic carbon (TOC), and PAH content. The results obtained are shown in Tables 1 and 2 . Sediment texture

Table 1

Initial characterization of sediments.

\begin{tabular}{lc}
\hline Parameter & Value \\
\hline Moisture content (\%) & 45 \\
Volatile solids/total solids, VS/TS (\%) & 5 \\
Fixed solids/total solids, FS/TS (\%) & 95 \\
Organic matter (\%) & 3.1 \\
pH & 7.85 \\
\hline
\end{tabular}


Table 2

PAH content of raw sediments.

\begin{tabular}{lllr}
\hline Parameter & Analytical method & Unit & Value \\
\hline Benzo (a) Antracene & EPA 8270C/96 & $\mathrm{mg} / \mathrm{kg}$ & 0.06 \\
Benzo (a) Pirene & EPA 8270C/96 & $\mathrm{mg} / \mathrm{kg}$ & 0.05 \\
Benzo (b) Fluorantene & EPA 8270C/96 & $\mathrm{mg} / \mathrm{kg}$ & $<0.05$ \\
Benzo (k) Fluorantene & EPA 8270C/96 & $\mathrm{mg} / \mathrm{kg}$ & $<0.05$ \\
Benzo (g,h,i) Perilene & EPA 8270C/96 & $\mathrm{mg} / \mathrm{kg}$ & $<0.05$ \\
Crisene & EPA 8270C/96 & $\mathrm{mg} / \mathrm{kg}$ & 0.13 \\
Dibenzo (a,e) Pirene & EPA 8270C/96 & $\mathrm{mg} / \mathrm{kg}$ & $<0.1$ \\
Dibenzo (a,l) Pirene & EPA 8270C/96 & $\mathrm{mg} / \mathrm{kg}$ & $<0.1$ \\
Dibenzo (a,i) Pirene & EPA 8270C/96 & $\mathrm{mg} / \mathrm{kg}$ & $<0.1$ \\
Dibenzo (a,h) Pirene & EPA 8270C/96 & $\mathrm{mg} / \mathrm{kg}$ & $<0.1$ \\
Dibenzo (a,h) Antracene & EPA 8270C/96 & $\mathrm{mg} / \mathrm{kg}$ & $<0.05$ \\
Indeno (1,2,3-c,d) Pirene & EPA 8270C/96 & $\mathrm{mg} / \mathrm{kg}$ & $<0.05$ \\
Pirene & EPA 8270C/96 & $\mathrm{mg} / \mathrm{kg}$ & 0.17 \\
Naftalene & EPA 8270C/96 & $\mathrm{mg} / \mathrm{kg}$ & 0.08 \\
Acenaftilene & EPA 8270C/96 & $\mathrm{mg} / \mathrm{kg}$ & $<0.05$ \\
Acenaftene & EPA 8270C/96 & $\mathrm{mg} / \mathrm{kg}$ & 0.06 \\
Fluorene & EPA 8270C/96 & $\mathrm{mg} / \mathrm{kg}$ & 0.08 \\
Fenantrene & EPA 8270C/96 & $\mathrm{mg} / \mathrm{kg}$ & 0.22 \\
Antracene & EPA 8270C/96 & $\mathrm{mg} / \mathrm{kg}$ & $<0.05$ \\
Fluorantene & EPA 8270C/96 & $\mathrm{mg} / \mathrm{kg}$ & 0.06
\end{tabular}

resulted in about $74 \%$ of sand and $24 \%$ of silt, while the gravel content was negligible. Since the PAH contamination of the raw sediments turned out to be very low, it was decided to increase the PAH content to a reasonable level, following the spiking procedure reported in Section 2.4. The slurry feed was then prepared by mixing the spiked sediments with tap water to reach a $10 \%$ solids concentration (i.e. $S / L=0.1$ weight of dry sediment/weight of slurry).

\subsection{Analytical methods}

The process performance was evaluated by sampling and analyzing PAHs in the sediments from the reactor at the beginning and at the end of each reaction cycle. This allowed to evaluate the process removal efficiency for the different compounds and PAHs classes.

PAH determinations were performed by following the analytical procedure described below. Analyses were always performed on triplicates and then the results obtained averaged.

The same determinations as for the initial characterization (i.e. moisture content, VS, FS, TOC) were also performed on a regular basis on slurry samples collected from the reactor, by following standard methods [20]. pH values were also measured during react, by using a standard probe. The supernatant after sediment settle was analytically characterized: namely, ammonia, nitrates, phosphate, chemical oxygen demand (COD) and PAHs content were determined. All these parameters were measured by following standard methodologies [21].

In order to assess the biological activity, oxygen uptake rate (OUR) measurements were carried out daily by means of batch tests: a $100 \mathrm{~mL}$ slurry sample was collected from the reactor $2 \mathrm{~h}$ after feeding the reactor with fresh sediments (in order to allow for slurry homogenization) and then transferred into a $250 \mathrm{~mL}$ Erlenmeyer flask where it was maintained under aerated and mixed conditions for a prefixed duration. Oxygen threshold limits were fixed to 7 and $6 \mathrm{mg} / \mathrm{L}$, and consumption by microorganisms was determined by recording oxygen concentration in the absence of aeration.

\subsection{Abiotic control tests}

In parallel with the activity on the SS-SBR plant, control tests were performed in order to assess the contribution of abiotic processes, and particularly of volatilization, to the removal rates observed in the reactor. A $500 \mathrm{~mL}$ Erlenmeyer flask was filled with contaminated sediments using the same Solid/Liquid $(S / L)$ ratio as in the biological reactor; however, before being spiked, the sediments were sterilized in autoclave, in order to avoid any biotic activity. The flask was kept under the same aerated and mixed conditions as in the SS-SBR plant. Periodical analyses of the PAHs content were performed in order to evaluate any loss due to volatilization

In order to avoid light degradation, the reactor was always kept covered with a dark material.

\subsection{Spiking procedure}

The sediments were spiked following the procedure outlined by Northcott and Jones [22]. Namely, a $250 \mathrm{~g}$ sediments sample was spiked with a fixed volume of a PAH stock mixture and $10 \mathrm{~mL}$ acetone, in order to obtain a given contamination. Compounds and concentrations were selected in order to simulate a real-case contamination due to the presence of both 3-rings (fluorene and anthracene) and 4-rings PAHs (pyrene and crysene). The total load was always evenly divided among the different compounds.

The sediment sample was first divided into four aliquots. An aliquot was first added into a mixer together with the PAH stock solution and acetone, and thoroughly mixed for $20 \mathrm{~s}$. Each further aliquot was then added to the system and mixed for $20 \mathrm{~s}$. The spiked sediments were then air-dried for $24 \mathrm{~h}$, and left in a dark room covered with an aluminum foil for 7 days.

\subsection{PAHs determination}

PAH determinations were performed according to the Test Methods for Evaluating Solid Waste, Physical/Chemical Methods (EPA, SW-846) [23]. Namely, sediments were extracted using the EPA 3540c method (Soxhlet Extraction): a $5 \mathrm{~g}$ sample of sediment, dried at $105^{\circ} \mathrm{C}$, was mixed with $5 \mathrm{~g}$ of anhydrous sodium sulfate, in order to absorb the residual humidity of the sample, and extracted using a $150 \mathrm{~mL}$ dichloromethane/acetone solution (1:1, $\mathrm{v} / \mathrm{v}$ ). The liquid sample obtained from the Soxhlet extraction was then concentrated, by solvent evaporation, enhanced through a low nitrogen flow. Once the sample was completely dried, a $1 \mathrm{~mL}$ acetone/dichloromethane solution was added to the vial, in order to dissolve the residual PAHs, thus providing the concentrated sample for GC-MS analysis. PAHs in the sediments samples were finally analyzed by GC-MS using an ${ }^{\odot}$ Agilent Technologies $6890 \mathrm{~N}$ Network GC System, equipped with a Split/Splitness ProgrammedTemperature injector, kept at $250^{\circ} \mathrm{C}$, and with a HP-5MS (5\% Phenyl Methyl Siloxane; $30 \mathrm{~m} \times 0.25 \mathrm{~mm}$ ID, $0.25 \mu \mathrm{m}$ df) capillary col$\mathrm{umn}$. The analytical procedure was performed in accordance to EPA $8270 \mathrm{C}$ method using Helium as carrier gas was, with a $1.0 \mathrm{~mL} / \mathrm{min}$ flow, whereas the split flow was $20 \mathrm{~mL} / \mathrm{min}$. The GC was coupled to an Agilent Technologies 5973 Network Mass Selective Detector, equipped with an hyperbolic quadrupole with $\mathrm{m} / \mathrm{z}$ values in the 16-800 amu (atomic mass units) range. All chromatograms were analyzed through the Agilent MSD Productivity ChemStation software for GC/MS System Data Analysis Application. The identification of each compound was obtained by comparing the measured mass spectra with those included in the NIST02 ${ }^{\circledR}$ library, and by comparing the retention times with those of standard mixtures. Besides, the internal standard method was applied for the quantification step.

\subsection{Operating conditions}

During the experimental activity, the operating conditions were modified by properly changing the value of the time-length of the cycle $\left(T_{\mathrm{C}}\right)$, the hydraulic residence time (HRT), the feed composi- 
Table 3

Experimental phases of the study.

\begin{tabular}{|c|c|c|c|c|}
\hline Phase & 1 & 2 & 3 & 4 \\
\hline \multirow[t]{2}{*}{ Feed load ${ }^{\mathrm{a}}(\mathrm{mg} / \mathrm{kg})$} & $30-40$ & $15-30$ & $30-40$ & $70-110$ \\
\hline & Anthracene & Anthracene & Anthracene & Anthracene \\
\hline \multirow{3}{*}{ Contaminants } & Fluorene & Fluorene & Fluorene & Fluorene \\
\hline & Pyrene & Pyrene & Pyrene & Pyrene \\
\hline & & Crysene & Crysene & Crysene \\
\hline Cycle length (d) & Variable & 7 & 7 & 7 \\
\hline HRT (d) & Variable & 44 & 70 & 70 \\
\hline VER & 0.16 & 0.16 & 0.10 & 0.10 \\
\hline Number of cycles & $1-4$ & $5-9$ & $10-17$ & $18-25$ \\
\hline
\end{tabular}

a Range of inlet concentrations in each phase.

tion and load $\left(C_{\mathrm{IN}}\right)$, based upon the observed performance of the reactor.

Feeding and drawing volumes were initially set to $0.8 \mathrm{~L}$ and then reduced to $0.5 \mathrm{~L}$ : correspondingly, the volumetric exchange ratios (VER), $V_{\mathrm{IN}} / V_{\mathrm{TOT}}$, were set to 0.16 and 0.10 , respectively. The cycle time-length was gradually reduced to $7 \mathrm{~d}$, that was used for most of the experimental phase. The times for the fill and draw phases were kept constantly equal to about $10 \mathrm{~min}$, so that almost the entire cycle was devoted to the aerated react phase.

No bioaugmentation was performed in consideration of the results obtained through preliminary batch tests, which had shown that a consistent removal of the contaminants could be achieved relying only on the indigenous microorganisms present in the sediments. Besides, operating the reactor without adding an external seed was considered more amenable for a possible full-scale implementation of the treatment.

The experimental activity performed can be divided in four phases, whose operating parameters and conditions are reported in Table 3. Values of feed loads refer to the concentration of contaminants measured in the inlet stream.

Phase 1 (from cycle 1 to 3 ) aimed at the start-up of the biological process in the SS-SBR plant through reactivation of the biomass originally present in the sediments. The PAHs feed mixture, at a concentration of about $40 \mathrm{mg} / \mathrm{kg}$, was constituted only by fluorene, anthracene and pyrene which were considered relatively more amenable for biodegradation than crysene. Variable cycle length and correspondingly different HRTs, were used during Phase 1 ; they were selected in order to get complete removal of the contaminants, so as to avoid their accumulation in the reactor. In the last cycle of this Phase, also crysene, i.e. a 4-ring PAH, was added to the spiking mixture, but in the mean time the total PAHs con- centration of the sediment was reduced, considering the expected lower biodegradability of crysene.

During Phase 2, which was operated from cycle 5 to cycle 9 , the length of the cycle was fixed to $7 \mathrm{~d}$ : by adopting a VER of 0.16 , the resulting HRT was $44 \mathrm{~d}$. The feed composition, as well as the total load, was maintained unchanged with respect to the last cycle of Phase 1.

In Phase 3, the organic load was slightly increased; this required also to raise the HRT, by modifying the value of VER, in order to provide the biomass with a longer react phase. No change of the feed composition was performed.

The influent load was further increased in Phase 4 whereas the operating parameters, such as HRT, VER and length of the cycle, were kept unchanged as well as the feed composition.

\section{Results}

\subsection{PAH removal}

The results reported in Fig. 2 show the overall performance of the SS-SBR unit during all the operating phases outlined in Table 3 and described in detail in Section 2.6. The data shown represent the total PAH concentration measured in the sediments fed to the unit at the beginning of each reaction cycle and in the sediments withdrawn at the end of the same cycle. It can be noticed that the performance of the process were immediately rather good with removal efficiencies of total PAHs raising during Phase 1 from about $60 \%$ up to $80 \%$ after only 3 operating cycles. As a consequence of the good process performance, it was possible to reduce the timelength of the cycle from the initial 20 days to about 10 days.

As far as the behaviour of each PAH compound is concerned, the results obtained are shown in Figs. 3 and 4 in terms of removal efficiency, calculated as follows:

$E \%=100 \times \frac{C_{\mathrm{IN}}-C_{\mathrm{OUT}}}{C_{\mathrm{IN}}}$

where $C_{\mathrm{IN}}$ and $C_{\mathrm{OUT}}$ refer to the measured concentration of the feeding and of the output sediments, respectively. These results indicate that the highest removal values were achieved for the 3-rings compounds, specifically for fluorene, whereas the 4-ring PAH pyrene and crysene, the latter added only in the last cycle of Phase 1, were only partially biodegraded. As expected, the lower number of rings was well correlated to a higher biodegradability.

During Phase 2, the composition of the influent was maintained unchanged whereas the length of the cycle was set at 7 days. Hence,

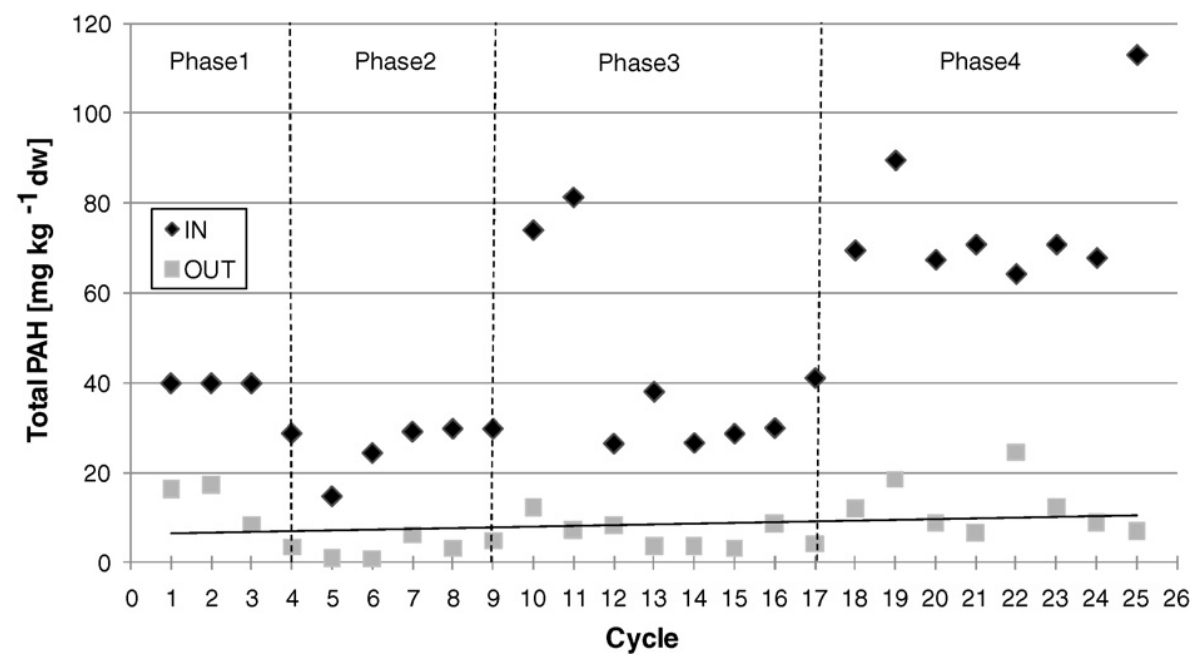

Fig. 2. Average inlet and outlet concentrations during all the operating phases. 


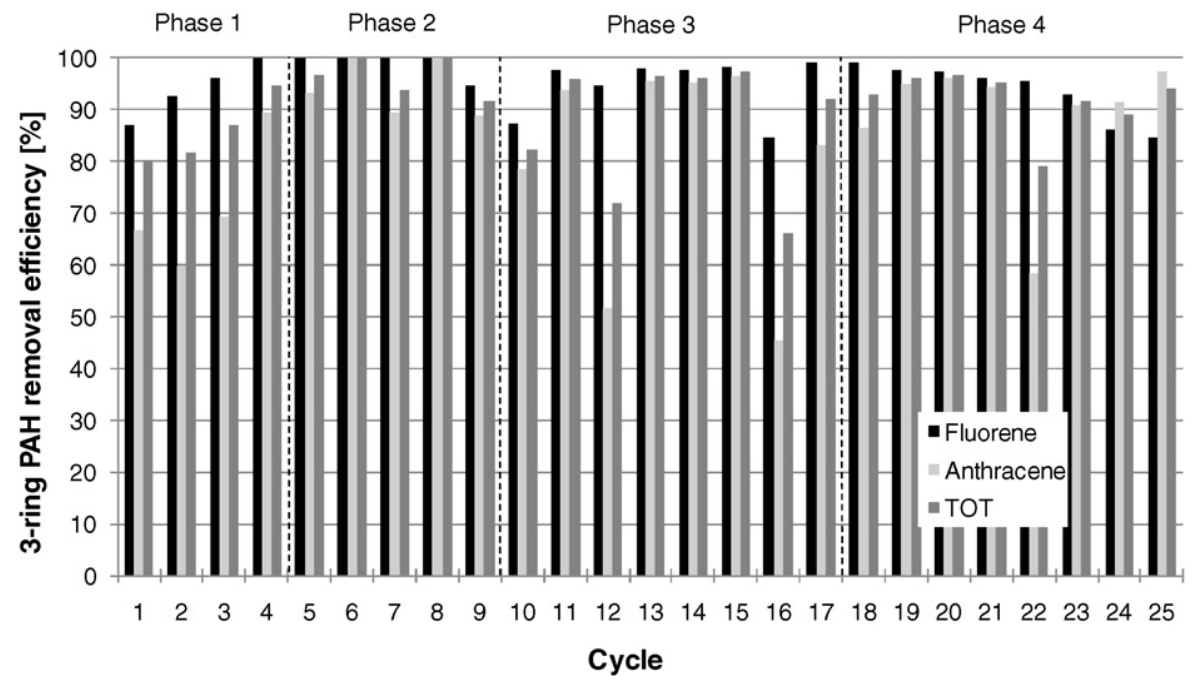

Fig. 3. Removal efficiencies of 3-rings PAHs during all the operating phases.

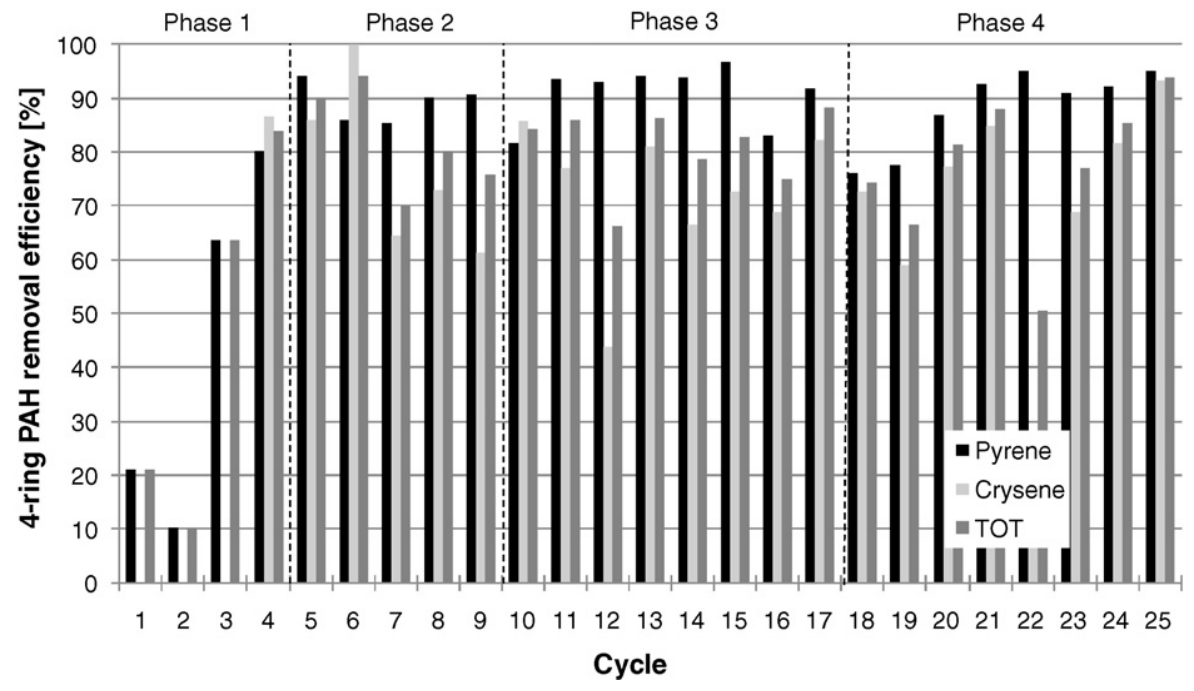

Fig. 4. Removal efficiencies of 4-rings PAHs during all the operating phases.

the total influent load was reduced to $30 \mathrm{mg} / \mathrm{kg} \mathrm{dw}$ in order to avoid accumulation of the compounds within the reactor, accounting for the expected lower biodegradability of crysene. As shown in Fig. 2, the overall process efficiency remarkably improved during Phase 2 , increasing up to $90 \%$, with the highest removal rates for fluorene and the lowest ones for crysene, as reported in Figs. 3 and 4.

During Phases 3 and 4 the biomass was exposed to increasing influent loads: therefore, the HRT was raised to higher values in order to provide microorganisms with a longer react time. The response of the system was rather good even when the inlet load reached the highest values. Although a slight decrease of the performance was observed for both the 3-ring and 4-ring compounds, the PAHs concentration in the sediments at the end of the cycle was mostly below $5 \mathrm{mg} / \mathrm{kg}$ during Phase 3, and below $12 \mathrm{mg} / \mathrm{kg}$ in Phase 4. As far as the single PAHs are concerned, the 3-ring compounds were characterized by higher removal rates with values far above $90 \%$. Once again, a slightly lower performance was obtained for PAHs belonging to the 4-ring class, with higher removal efficiencies for pyrene than crysene.

Analyses on the supernatant from sediment-slurry settle after the react phases always showed very low concentrations of PAHs (Table 4).
Besides, the abiotic tests showed that loss of PAHs due to volatilization were always negligible.

\subsection{OUR}

The oxygen uptake rate (OUR) was measured in batch tests filled with samples of sediments collected from the lab-scale SBR, in order to obtain a deeper understanding of the removal kinetics.

Table 4

Average concentrations in the supernatant from sedimentslurry separation after react.

\begin{tabular}{lc}
\hline Parameter & Value $\left(\mathrm{mg} \mathrm{L}^{-1}\right)$ \\
\hline Ammonia & 0.78 \\
Nitrates & 0.05 \\
Phosphates & $<0.1^{\mathrm{a}}$ \\
COD $_{\text {slurry }}$ & 4000 \\
COD $_{\text {liquid phase }}$ & 250 \\
COD $_{1.2} \mu \mathrm{m}^{\mathrm{b}}$ & 220 \\
PAHs & $0.02^{\mathrm{a}}$ \\
\hline
\end{tabular}

Detection limit

b After filtration at $1.2 \mu \mathrm{m}$. 


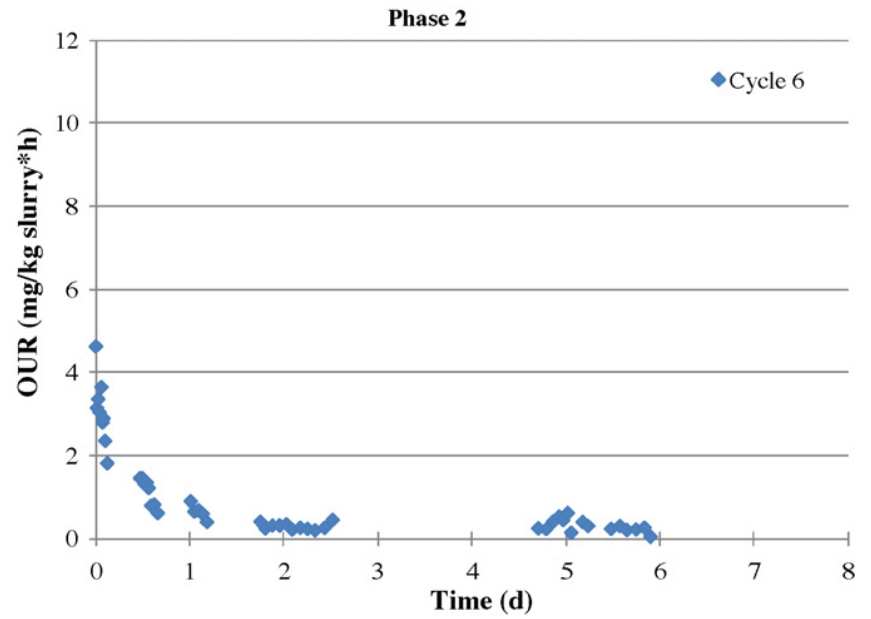

Fig. 5. Typical OUR time-profile in Phase 2.

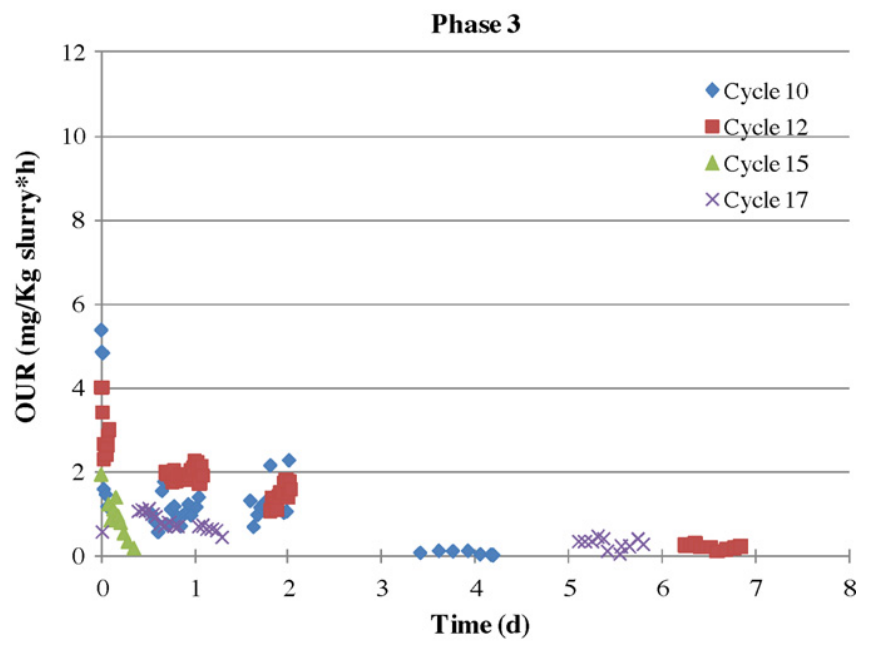

Fig. 6. Typical OUR time-profile in Phase 3.

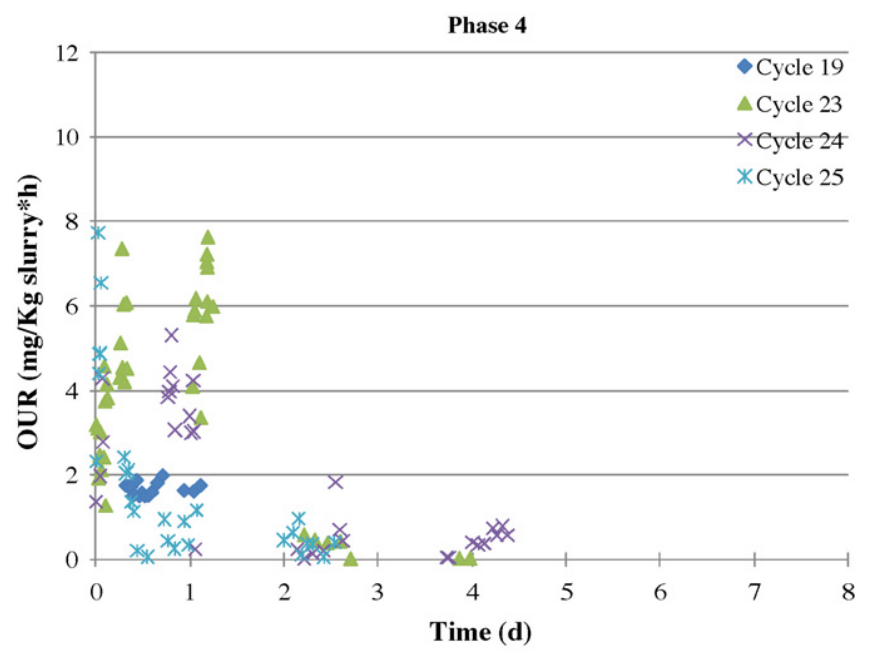

Fig. 7. Typical OUR time-profile in Phase 4.

The results of these measurements are shown in Figs. 5-7, which represent the typical time evolution of the OUR measured during the operating cycles in Phases 2, 3 and 4, respectively. Although a general variability can be noted for all the data obtained, due to the heterogeneity of the collected samples, however useful information were drawn from the OUR time-profiles.

Despite some differences in the absolute values, the OUR trends show basically a similar pattern. OUR had initially relatively high values and then decreased slowly until it achieved baseline values. This trend indicates that, in most cases, PAH-removal started immediately after the beginning of the react phase with no lag phase; the removal proceeded at a very high rate in the first day of the cycle and then slowed down when the exogenous substrate became less available. Looking more carefully at the OUR data of Fig. 7, a slight difference can be noted. Despite the wide variability, in cycles 23 and 24, it can be seen that the initial peak did not occur immediately after the beginning of the cycle, instead it was shifted downward with time. Moving from cycle 23 to cycle 24, the occurrence of such a peak was anticipated and, at cycle 25 , it is shown at time $=0$. Such a pattern may reflect a recovery process from a partial inhibition which might have occurred in the previous cycles. This observation seems to be confirmed by the data of Figs. 3 and 4: a progressive improvement of $\mathrm{PAH}-$ removal efficiency took place along the same cycles, particularly for the 4-rings compounds. Correspondingly, the total $\mathrm{PAH}$ concentration in the output from the reactor decreased progressively from about $25 \mathrm{mg} / \mathrm{kg}$ (cycle 22) to below $6 \mathrm{mg} / \mathrm{kg}$ (cycle 25 ).

The low values of the OUR achieved after approximately 3 days of cycle operation, suggest that from this time onward the microbial activity was related to endogenous respiration only. Since the duration of the cycle was set at 7 days, this indicates that microorganisms did not show any specific activity connected to exogenous degradation for roughly $50 \%$ of the whole cycle time. However, measurements of the PAH concentrations on sediments revealed that not all the PAH load had been removed after 3 days of operation. For instance, at the end of each reaction cycle the removal efficiency of crysene was notably lower than that one measured for the other PAHs, leaving some unreacted crysene in the sediments. This suggests that the microorganisms were not capable of using crysene alone as substrate after the other PAHs had been already removed.

Based on the OURs data, the following average values of the maximum and the endogenous OURs $\left(\mathrm{OUR}_{\max }\right.$ and OUR $\mathrm{end}_{\text {end }}$, respectively) were obtained:

$$
\begin{aligned}
& \text { OUR }_{\text {max }}=5.8(4.01-7.73) \mathrm{mgO}_{2} \mathrm{~kg}_{\text {slurry }}{ }^{-1} \mathrm{~h}^{-1} \\
& \text { OUR }_{\text {end }}=0.05(0.02-0.10) \mathrm{mgO}_{2} \mathrm{~kg}_{\text {slurry }}{ }^{-1} \mathrm{~h}^{-1}
\end{aligned}
$$

\subsection{VS and TOC}

As shown in Figs. 8 and 9, both VS and TOC of the outlet sediments (values referred to dry sediments) notably increased through Phases 1 and 2 of the experimental activity. The VS and TOC of the sediments at the end of each cycle were almost always much higher than those of the inlet sediments. This observation can be probably correlated to an increase of the microbial population in the reactor, due to the intense biodegradation activity. A somehow different behavior was observed during Phases 3 and 4, where the VS/TOC values measured in the outlet sediments were often equal or even lower than the ones measured in the inlet sediments. This may be probably explained with the fact that the cycle duration was in this case too long with respect to the effective duration of the microbial removal process, that was about 3 days based on the OUR measurements. The instauration of an endogenous period of about 3 days per cycle probably led to a gradual decrease of the biomass concentration in the system, which resulted in both VS and TOC reduction. 


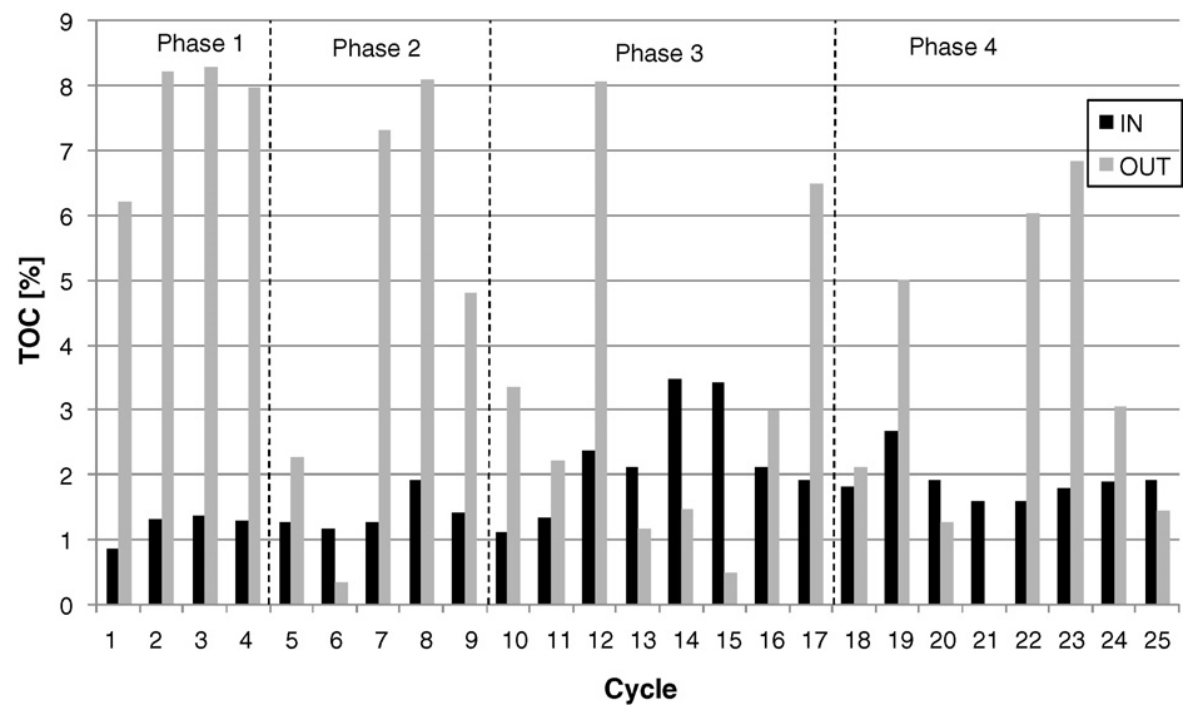

Fig. 8. Average inlet and outlet TOC concentrations during all the operating phases.

\section{Discussion}

Combining the results obtained from different parameters provided useful indications to obtain a better understanding of the mechanisms at the base of the observed removal process.

The microbial activity was considered the main responsible for the contaminant removal, instead of abiotic processes (such as volatilization) or only release into the liquid phase (PAH concentrations in the supernatant from sediment settle after react was always negligible). Besides, this microbial activity was mainly attributed to the oxidation of PAHs rather to that of the residual organic matter of sediments. This conclusion was drawn by looking at the OUR patterns, which were also pretty well correlated to the profiles of PAH-removal efficiency. For instance, beside the high peaks at the beginning of each cycle after feeding, the OUR time-profiles within the cycles where characterized by a general increasing trend along with a longer reaction time at increasing influent loads.

About the single compounds investigated, it was observed that the microorganisms were not capable of using crysene alone as substrate after the other PAHs had been removed. This suggests that cometabolism might be exploited for improving removal efficiency and eventually allowing degradation of different compounds belonging to the class of PAHs.

The OUR data also gave clear indication of the effective duration of the react phase: the establishment of endogenous conditions far before the end of the cycle, represented by the low values assumed by OUR, suggested that a reduction of the length of the cycle might be introduced so as to increase the productivity of the plant. This would also avoid the progressive decrease of the VS content at the depletion of the exogenous substrate.

This observation is somehow in agreement with a previous paper, where the duration of the cycle was reduced to 3.5 days, even if at a much lower PAH inlet concentration [19].

Although the collected OUR data allowed to draw such useful information, however they were affected by a wide variability due to the heterogeneity of the samples. Therefore, the procedure followed to measure the OUR profiles should be optimized, e.g. by replacing the external batch tests with direct measurements within the reactor or by adopting an automated system such that one used by Giordano et al. in their study [19].

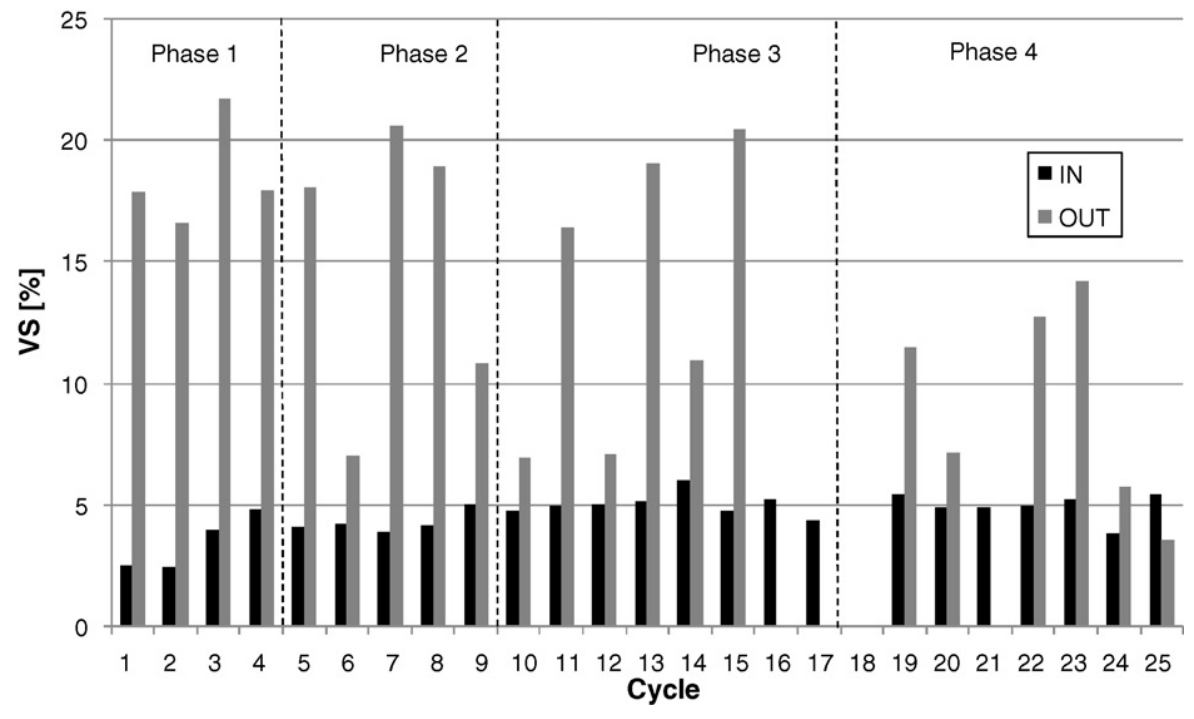

Fig. 9. Average inlet and outlet VS concentrations during all the operating phases. 


\section{Conclusions}

The present paper reports of an experimental activity carried out in a lab-scale SS-SBR fed with freshly PAH spiked sediments and without the addition of an external seed.

The removal efficiency rapidly improved during the study and in the last phase achieved average values above $80 \%$ for a total feed load of about $70 \mathrm{mg} / \mathrm{kg}$. The best performance were observed for the 3-rings compounds with respect to the 4rings PAHs: particularly, the highest removal was obtained for fluorene, whereas the lowest one for crysene. Besides, crysene seemed to be preferably biodegraded in the presence of other PAHs, suggesting that cometabolism took place during the react phase.

Since the removal process in the SBR plant did not show any appreciable lag phase, instead the disappearance of PAHs occurred since the beginning of the experimental activity with appreciable removal (about 60\%), it was assumed that microbial aerobic $\mathrm{PAH}$-degrading species were already present in the raw sediments. Setting-up a controlled system in terms of influent contaminant load, aeration and mixing conditions, and also the addition of sediments in a slurry phase, probably determined reactivation and then enrichment of such species.

The OUR measurements gave a clear indication of the microbial activity: for instance, the removal rate was quite high at the beginning of the cycle, whereas decreased appreciably after only 3 days due to the establishment of endogenous respiration conditions. The OUR data provided useful information for the understanding of the process behavior and may thus constitute an useful tool for the optimization of the operative cycle of the plant: for instance, the feed load, the VER and/or the length of the react phase might be modified according to the kinetics highlighted by the OUR time-profiles within typical operative cycles. Furthermore, the aeration equipment might be managed so as to avoid a lack of available oxygen and to limit air waste.

The SS-SBR has proven to be a valid system for the remediation of PAH-contaminated sediments, while offering a high flexibility to adapt the process to the characteristics of the compounds to be treated. For instance, by properly controlling the value of the VER it was possible to limit the pollutant load the biomass was exposed to so as to avoid inhibition phenomena.

In view of a full-scale application, a liquid/solid separation step should be necessarily introduced, thus allowing the reuse of the treated sediments and the recycle of the liquid solution to the SBR reactor, in order to reduce freshwater needs.

Besides, effects related to aging processes should also be taken into account since might negatively affect the removal efficiency by reducing bioavailability of PAHs to microorganisms.

\section{References}

[1] S.Y. Yuan, S.H. Wei, B.V. Chang, Biodegradation of polycyclic aromatic hydrocarbons by a mixed culture, Chemosphere 41 (2000) 1463-1468.

[2] H.H. Tabak, P. Lens, E.D. van Hullebusch, W. Dejonghe, Developments in bioremediation of soil and sediments polluted with metals and radionuclides- 1 Microbial processes and mechanisms affecting bioremediation of metal contamination and influencing metal toxicity and transport, Rev. Environ. Sci. Bio./Technol. 4 (2005) 115-156.

[3] A. Chauhan, J.G. Fazlurrahman, R.K. Oakeshott Jain, Bacterial metabolism of polycyclic aromatic hydrocarbons: strategies for bioremediation, Indian J. Microbiol. 48 (2008) 95-113.

[4] M.P. Cuypers, J.T.C. Gtotenhuis, W.H. Rulkens, Characterisation of PAHcontaminated sediments in a remediation perspective, Water Sci. Technol. 37 (6) (1998) 157-164

[5] E. Ferrarese, G. Andreottola, I.A. Opera, Remediation of PAH-contaminated sediments by chemical oxidation, J. Hazard. Mater. 152 (2008) 128-139.

[6] C.E. Cerniglia, Biodegradation of polycyclic aromatic hydrocarbons, Biodegradation 3 (1992) 351-358.

[7] L. Lei, A.P. Khodadoust, M.T. Suidan, H.H. Tabak, Biodegradation of sedimentbound PAHs in field-contaminated sediment, Water Res. 39 (2005) 349-361.

[8] W. Rulkens, Introduction to the treatment of polluted sediments, Rev. Environ. Sci. Bio./Technol. 4 (2005) 213-221.

[9] L.A. Launen, V.H. Buggs, M.E. Eastep, R.C. Enriquez, J.W. Leonard, M.J. Blaylock, J.W. Huang, M.M. Haggblom, Bioremediation of polyaromatic hydrocarboncontaminated sediments in aerated bioslurry reactors, Bioremed. J. 6 (2002) $124-141$.

[10] D. Dean-Ross, Biodegradation of selected PAH from sediment in bioslurry reactors, Bull. Environ. Contam. Toxicol. 74 (2005) 32-39.

[11] A.R. Johnsen, L.Y. Wick, H. Harms, Principles of microbial PAH-degradation in soil, Environ. Pollut. 133 (2005) 71-84.

[12] D.P. Cassidy, S. Efendiev, D.M. White, Comparison of CSTR and SBR bioslurry reactor performance, Water Res. 34 (18) (2000) 4333-4342.

[13] F. Abbondanzi, L. Bruzzi, T. Campisi, A. Frezzati, R. Guerra, A. Iacondini, Biotreatability of polycyclic aromatic hydrocarbons in brackish sediments: Preliminary studies of an integrated monitoring, Int. Biodeter. Biodegr. 57 (2006) 214-221.

[14] P.A. Wilderer, R.L. Irvine, M. Goronszy, Sequencing Batch Reactor Technology, Scientific and Technical Report No. 10, IWA Publishing, London, UK, 2001.

[15] A. Carucci, A. Chiavola, M. Majone, E. Rolle, Treatment of tannery wastewater in a sequencing batch reactor, Water Sci. Technol. 40 (1) (1999) 253-259.

[16] A. Chiavola, R. Baciocchi, R.L. Irvine, R. Gavasci, P. Sirini, Aerobic biodegradation of 3-chlorophenol in a Sequencing Batch Reactor. Effect of cometabolism, Water Sci. Technol. 50 (10) (2004) 235-242.

[17] J. Doyle, S. Watts, D. Solley, J. Keller, Exceptionally high-rate nitrification in sequencing batch reactors treating high ammonia landfill leachate, Water Sci. Technol. 43 (3) (2001) 315-322.

[18] G. Ma, N.G. Love, Creating anoxic and microaerobic conditions in sequencing batch reactors treating volatile BTEX compounds, Water Sci. Technol. 43 (3) (2001) 275-282.

[19] S. Giordano, L. Stante, F. Pirozzi, R. Cesaro, G. Bortone, Sequencing batch reactor performance treating PAH contaminated lagoon sediments, J. Hazard. Mater. B119 (2005) 159-166.

[20] APAT, Agenzia per la Protezione dell'ambiente e per i servizi tecnici, Guida tecnica sui metodi di analisi dei suoli contaminati, Italy, 2003.

[21] APHA, Standard Methods for the Examination of Water and Wastewaters, 17th ed., American Public Health Association, Washington, DC, 1992.

[22] G.L. Northcott, K.C. Jones, Spiking hydrophobic organic compounds into soil and sediment: a review and critique of adopted procedures, Environ. Toxicol. Chem. 19 (10) (2000) 2418-2430.

[23] U.S. EPA, Test Methods for Evaluating Solid Waste, Physical/Chemical Methods, SW-846, Washington, DC, 1995. 